\title{
Modelling the Effects of Cracking of Lake Sediments During Drying on Acid Generation and Acid Transport to the Water Column Upon Rewetting
}

\author{
$\underline{\text { Freeman J Cook }}^{a}$ and Luke M Mosley ${ }^{b}$ \\ ${ }^{a}$ Freeman Cook and Associates, The University of Queensland and Griffith University \\ ${ }^{b}$ University of Adelaide \\ Email:freeman@freemancook.com.au
}

\begin{abstract}
An extreme "millennium" drought from 2007 to 2010 resulted in the lowest River Murray levels (1.75 m decline from average) in over 90 years of records at the end of the river system in South Australia. This resulted in low inflows of water to Lake Alexandrina and Lake Albert and exposed large areas of soils on the lake margins to drying. This drying caused the sediments to shrink and crack with the formation of large columnar blocks of soil.

Sediment physical properties were measured on samples taken from the lake at different locations (Cook et al., 2011) and used to develop a HYDRUS2D/3D model to determine the oxygen penetration into cylindrical peds (soil blocks) with varying radii $(0.05,0.1,0.15 \mathrm{~m})$, depth of cracks $(0.1,0.2,0.5 \mathrm{~m})$ and water table depth (WTD) $(0.1,0.2,0.5,1.0 \mathrm{~m})$. The peds were assumed to be initially saturated and lost water due to drainage (to the water table) and evaporation (potential $4 \mathrm{~mm} \mathrm{day}^{-1}$ ), from both the top and sides of the ped. Oxygen $\left(\mathrm{O}_{2}\right)$ penetrated the peds due to gas advection (as water was lost), and diffusion, and was lost due to oxygen consumption by organic matter ( $98 \%$ of the sink strength) and pyrite $(2 \%)$. This drying and oxygenation process was modelled for 1000 days and the $\mathrm{O}_{2}$ concentrations recorded. $\mathrm{O}_{2}$ penetrated to the center of the ped at the sediment surface, but the radial penetration decreased with depth (Figure 1) and the concentration varied little after the first day due to near balance between diffusion and consumption.

Pyrite oxidation and hence the formation of acidity in the peds was modelled using a first-order chain reaction based on oxygen concentration. This resulting in a slow increase in $\mathrm{Fe}^{2+}$ concentration with time (Figure 2). Various scenarios were tested to describe rewetting and hence transport of acidity to the lake; a rising water table with seepage from the crack and surface, inundation of the surface and crack, and water flow into the ped from the crack and seepage at the surface. These were compared to simulations of the sediment without cracks as a control, with two rewetting scenarios: rewetting due to watertable rise, and surface inundation. The mass of acidity generated from oxidation of pyrite was most sensitive to increasing ped radius, and then linearly with time. Acid generation within the peds was greater than in sediment without cracks. The scenario where the water table rose from below resulted in the most acidity transported from the soil to the lake water, while the scenario where both the surface of the ped and crack were instantaneous inundated resulted in the least acidity transported to the lake water. These results have implications for how lake rewetting is allowed to occur.
\end{abstract}

Keywords: $\quad$ Acid flux, acid sulfate soils, pyrite oxidation, solute transport, water quality 
Freeman J Cook and Luke M Mosley, Modelling effects of cracking on during drying on: acid generation and acid transport to the water column upon rewetting

\section{INTRODUCTION}

The "Millennium" drought from 2007 to 2010 resulted in the lowest River Murray levels (1.75 m decline from average) in over 90 years of records at the end of the river system in South Australia. This resulted in low inflows of water to Lake Alexandrina and Lake Albert, which exposed large areas of sediments on the lake bed to drying. Upon drying these sediments cracked. As the sediments contained pyrite this generated acidity as the pyrite oxidized (Earth systems, 2010; Fitzpatrick et al., 2008; Hipsey et al., 2010; Hipsey et al., 2014; Cook, 2011). The extent of the oxidation of these cracked sediments was estimated by Cook et al. (2011) and simple estimates of the flux of acidity to the lake water was estimated from the oxygen concentrations (Cook et al., 2012) using numerical modelling and for sediments without cracks using analytical models (Cook et al., 2012; Cook \& Mosley, 2012, 2013).

Understanding the effect of cracking and the formation of columnar peds on the oxidative reaction of materials in lake sediments to drying and rewetting is important in understanding effects on water quality. Comparison with one-dimensional flow from a planar surface is required if enhancement of generation of reactive solutes and transport of these to the lake water quality upon rewetting is to be understood. These investigations may also assist in design of lake refilling schemes to minimize impacts on water quality.

In this study we have used more sophisticated numerical modelling methods to get an improved estimate of the acidity generation and distribution in both cracked and non-cracked sediments at one site Boggy Creek (Cook et al., 2011). The modelling was performed with

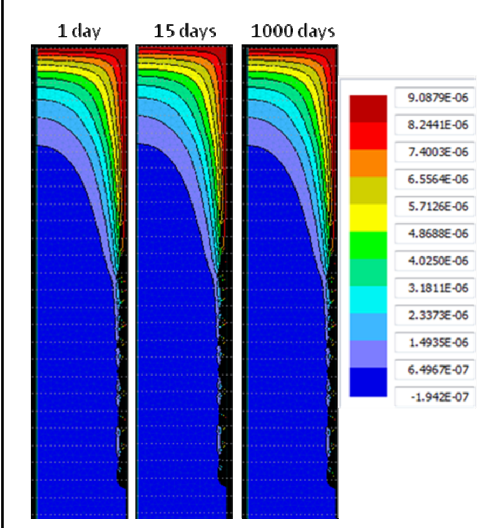

Figure 1. Oxygen concentration $\left(\mathrm{g} \mathrm{cm}^{-3}\right)$ profiles for sediment 1,15 and 1000

days after drainage and evaporation. For a ped with $0.1 \mathrm{~m}$ radius, crack depth $0.5 \mathrm{~m}$ and WTD $0.5 \mathrm{~m}$. the HYDRUS2D/3D software using the chained reaction process. This allowed the acidity generated within the peds to be modelled. Peds with different radii, crack depth and water table depth were considered, to determine the effect of these variables on the generation of acidity.

Different scenarios were investigated upon rewetting of a cracked surface; water table rise to the surface, filling of the crack only, and inundation of both the crack and surface of the ped. Similarly, for the planar surface case, we considered water table rise and surface inundation as options.

\section{METHODS}

Sediment physical properties were measured on samples taken from the lake at different locations (Cook et al., 2011) and used to develop a HYDRUS2D/3D model to determine the oxygen penetration into cylindrical peds (soil blocks) with varying radii $(0.05,0.1,0.15 \mathrm{~m})$, depth of cracks $(0.1,0.2,0.5 \mathrm{~m})$ and water table depth (WTD) $(0.1$, $0.2,0.5,1.0 \mathrm{~m})$. The ped was initially fully saturated and at time zero the water table was assumed to decrease to the depth of the crack and remain constant for 1000 days. In simulations where the effect of water table depth was tested, the water table was allowed to decrease to greater depths. The peds lost water due to drainage (to the water table) and evaporation (potential evaporation $4 \mathrm{~mm} \mathrm{day}^{-1}$ ), from both the top and sides of the ped. A Dirchlet boundary condition was applied at the surface of the sediment and the crack surface with an oxygen concentration of $0.273 \mathrm{~kg} \mathrm{~m}^{-3}$. Oxygen was assumed to be consumed by organic matter decomposition and pyrite oxidation with the latter representing $2 \%$ of the total sink (following Rigby et al., 2006). Oxygen $\left(\mathrm{O}_{2}\right)$ penetrated the peds due to gas advection (as water was lost), and diffusion, and was lost due to oxygen consumption by organic matter ( $98 \%$ of the sink strength) and pyrite (2\%). This drying and oxygenation process was modelled for 1000 days and the $\mathrm{O}_{2}$ concentrations recorded (Figure 1).

Pyrite oxidation and hence the formation of acidity in the peds was

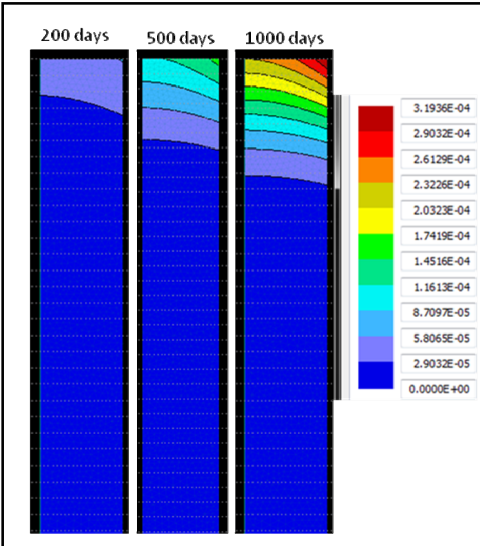

Figure 2. Oxidised pyrite concentration $\left(\mathrm{g} \mathrm{cm}^{-3}\right)$ profiles for sediment 200, 500 and 1000 days after drainage and evaporation. For a ped with $0.1 \mathrm{~m}$ radius, crack depth $0.5 \mathrm{~m}$ and WTD $0.5 \mathrm{~m}$. modelled using a first-order chain reaction based on oxygen concentration with a rate of $0.018\left(\right.$ day $\left.^{-1}\right)$ 
Freeman J Cook and Luke M Mosley, Modelling effects of cracking on during drying on: acid generation and acid transport to the water column upon rewetting

(Hipsey et al., 2010). This resulted in a slow increase in $\mathrm{Fe}^{2+}$ concentration (Figure 2) in the soil. Since the reaction of pyrite requires $15 / 4$ moles of $\mathrm{O}_{2}$ per mole of pyrite and results in 4 moles of protons the resulting product of the chain reaction will result in approximately $1 / 2$ of the actual acidity $(15 / 4 \times 4 / 32=0.47)$.

The release of this acidity into the lake water was simulated using three different scenarios, where at time zero; (Scenario 1) the water table rises from the depth during the drying phase to the ped surface, (Scenario 2) water fills the crack and wets the ped radially, (Scenario 3) and water inundates the ped crack and surface at the same time. The initial conditions were those after 1000 days in the drying phase. The simulation was then run for 1000 days and the amount of $\mathrm{Fe}^{2+}$ lost from the sediment recorded. Mass balances were checked: errors in $\mathrm{Fe}^{2+}$ mass were less than $10 \%$ except for the scenario where the surface and crack were inundated. For this scenario the mass lost was small (generally less than 1\%) and the small mass changes exacerbated the mass balance error, so higher mass balance errors were accepted.

One dimensional flux drying from the planar surface was also simulated for comparison with the ped simulations. Similarly rewetting was also simulated with rewetting via water table rise (Scenario 4) and inundation of the sediment surface (Scenario 5).

\section{RESULTS AND DISCUSSION}

Acidity generation increased due to the formation of even modest cracks (100 mm depth and ped radius) with various water table depths. The proportional increase compared to the planar surface was calculated as:

$P=\left(\mathrm{Fe}^{2+}\right.$ (cracked) $-\mathrm{Fe}^{2+}$ (planar) $) / \mathrm{Fe}^{2+}$ (planar). $P$ increase decreased from $190 \%$ with a water table depth of $100 \mathrm{~mm}$, to $90 \%$ when the water table was $1000 \mathrm{~mm}$ (Figure 3). This is decrease in radial oxygen penetration with depth (Figure 1), so less of the pyrite is oxidized deeper in the soil. However, the total amount of acidity generated does increase with water table depth for both planar and cracked sediments.

This suggests that modest cracking near the lake water's edge during drying of the lake could greatly enhance the acidity formation process. The acidity generated within the peds increased with decreasing radii of the peds, increasing depth of the cracks and also reduction in the water table depth (Figure 4 ). The increase in acidity with radius ( $r$ ) does not take into account the increase in volume of the sediment in the ped. When the volume of the sediment is accounted for (proportional to $r^{2}$ ) the acidity per sediment surface area was found to decrease by about $2-3$ fold.

Upon rewetting the mass of acidity is rapidly lost through the crack and ped surface for Scenario 1, more slowly with time for scenario 2 through the ped surface and hardly any at all for Scenario 3 (Figure 5). By comparison for the planar (noncracked) surface, acidity is lost more slowly and when the water table rises to the surface (Scenario 4) and again hardly any acidity is lost when the surface is inundated (Scenario 5). Similar patterns occurred for all combinations of radius, crack depth and water table depth. The proportion lost after 1000 days for these combinations are given in Table 2.

The practical implication of these results is that if possible, the water level in the lake following a drying period should be allowed to rise as fast as possible, so that both the surface and the cracks

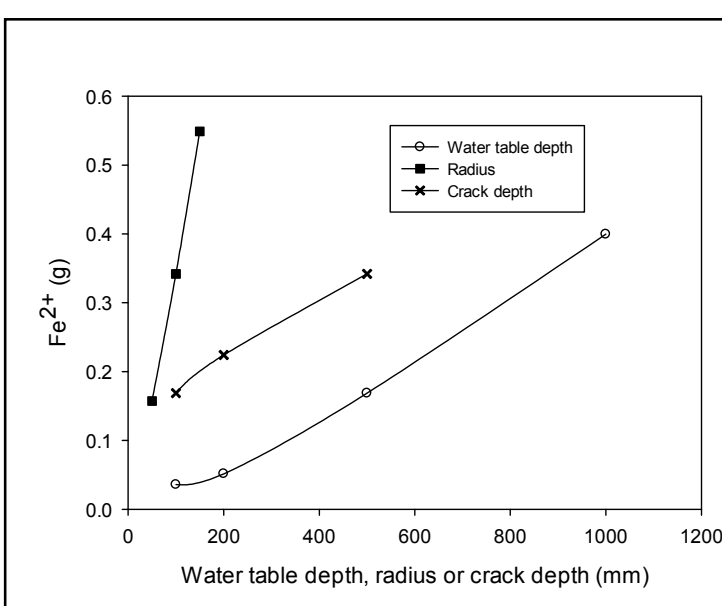

Figure 4. Increase in $\mathrm{Fe}^{2+}$ generated within peds with: radius (crack depth $500 \mathrm{~mm}$ and water table depth $500 \mathrm{~mm}$ ); crack depth (radius $100 \mathrm{~mm}$ and water table depth $500 \mathrm{~mm}$ ); and water table depth (radius $100 \mathrm{~mm}$ and crack depth $100 \mathrm{~mm}$ ). 
Freeman J Cook and Luke M Mosley, Modelling effects of cracking on during drying on: acid generation and acid transport to the water column upon rewetting

can be inundated simultaneously. This will result in the advection of water into the peds, pushing solutes away from both the crack surface and top of the ped. A similar suggestion was made by Cook and Mosley (2013). This will keep most of the solute, in this case acidity, within the lake sediment. Although this acidity will gradually diffuse out a greater proportion will likely be converted back to pyrite or other less mobile constituents.

The worst possible result would occur if the lake is allowed to fill slowly, with the water table gradually rising. This scenario is predicted to transport most of the acidity up the sediment column and into the lake water. The same result occurs for non-cracked sediments but at a slower rate. On the other hand, if the solutes in the sediment require removal, then this is the best approach to use.

The exact scenarios simulated here are unlikely to occur in practice: any rise in lake levels following droughts is likely to represent combination of these mechanisms. However, the scenarios provide a clear understanding of the consequences of alternative lake level rise scenarios and offer some insight into how to manage this process. If

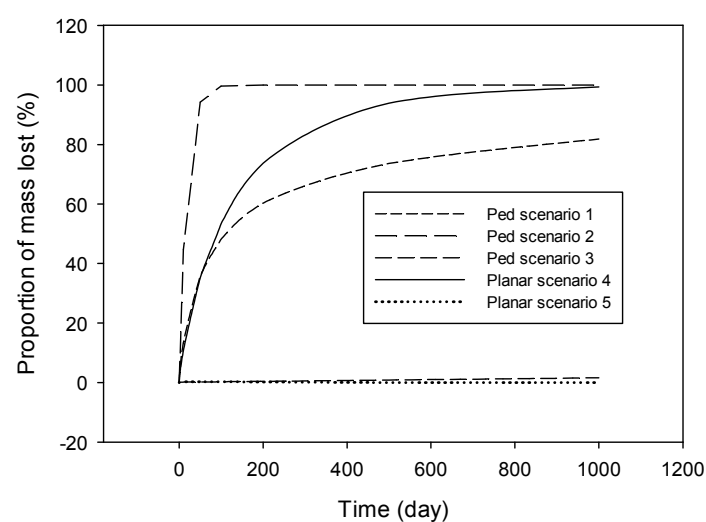

Figure 5. Loss of $\mathrm{Fe}^{2+}$ from peds with, radius $100 \mathrm{~mm}$, crack depth $500 \mathrm{~mm}$ and water table depth

$500 \mathrm{~mm}$ during drying, for rewetting scenarios $1,2,3$; and for planar surface with water table depth $500 \mathrm{~mm}$ during drying, and rewetting scenarios 4 and 5.

the water available does not allow for rapid rise, it may be productive to build temporary bunds to store water which can then be rapidly release into an area that is to be rewetted. This may be a useful way to rewet billabongs that generate acidity, in the future.

Table 1. Percentage of $\mathrm{Fe}^{2+}$ lost from sediment to lake water in 1000 days for various radii $(r)$, water table depth (WTD) and crack depth $(z)$.

\begin{tabular}{|c|c|c|c|c|c|c|c|c|c|c|c|c|}
\hline Scenario & $\begin{array}{l}r \\
(\mathrm{~mm})\end{array}$ & $\begin{array}{l}\text { WTD } \\
(\mathrm{mm})\end{array}$ & $\begin{array}{l}z z \\
(\mathrm{~mm})\end{array}$ & $\begin{array}{l}\mathrm{Fe}^{2+} \\
\text { loss } \\
(\%)\end{array}$ & $\begin{array}{c}r \\
(\mathrm{~mm})\end{array}$ & $\begin{array}{l}\text { WTD } \\
(\mathrm{mm})\end{array}$ & $\begin{array}{l}z \\
(\mathrm{~mm})\end{array}$ & $\begin{array}{l}\mathrm{Fe}^{2+} \\
\text { loss } \\
(\%)\end{array}$ & $\begin{array}{c}r \\
(\mathrm{~mm})\end{array}$ & $\begin{array}{l}\text { WTD } \\
(\mathrm{mm})\end{array}$ & $\begin{array}{l}z \\
(\mathrm{~mm})\end{array}$ & $\begin{array}{l}\mathrm{Fe}^{2+} \\
\text { loss } \\
(\%)\end{array}$ \\
\hline \multicolumn{13}{|c|}{ Increasing $z, r=100 \mathrm{~mm}$ and $\mathrm{WTD}=500 \mathrm{~mm}$} \\
\hline 1 & 100 & 500 & 100 & 81 & 100 & 500 & 200 & 82 & 100 & 500 & 500 & 82 \\
\hline 2 & 100 & 500 & 100 & 100 & 100 & 500 & 200 & 100 & 100 & 500 & 500 & 100 \\
\hline 3 & 100 & 500 & 100 & $\mathbf{0}$ & 100 & 500 & 200 & $\mathbf{0}$ & 100 & 500 & 500 & 2 \\
\hline 4 & - & 500 & - & 99 & & & & & & & & \\
\hline 5 & - & 500 & - & $\mathbf{0}$ & & & & & & & & \\
\hline \multicolumn{13}{|c|}{ Increasing $z, r=100 \mathrm{~mm}$ and WTD $=200 \mathrm{~mm}$} \\
\hline 1 & 100 & 200 & 100 & 83 & 100 & 200 & 500 & 81 & 100 & 200 & 1000 & 81 \\
\hline 2 & 100 & 200 & 100 & 100 & 100 & 200 & 500 & 100 & 100 & 200 & 1000 & 100 \\
\hline 3 & 100 & 200 & 100 & 0 & 100 & 200 & 500 & $\mathbf{0}$ & 100 & 200 & 1000 & $\mathbf{0}$ \\
\hline 4 & - & 200 & - & 99 & 100 & 200 & 500 & 99 & 100 & 200 & 1000 & 99 \\
\hline 5 & - & 200 & - & $\mathbf{0}$ & 100 & 200 & 500 & $\mathbf{0}$ & 100 & 200 & 1000 & 0.1 \\
\hline \multicolumn{13}{|c|}{ Increasing $r, z=500 \mathrm{~mm}$ and WTD $=500 \mathrm{~mm}$} \\
\hline 1 & 50 & 500 & 500 & 81 & 100 & 500 & 500 & 81 & 150 & 500 & 500 & 100 \\
\hline 2 & 50 & 500 & 500 & 100 & 100 & 500 & 500 & 100 & 150 & 500 & 500 & 100 \\
\hline 3 & 50 & 500 & 500 & $\mathbf{0}$ & 100 & 500 & 500 & $\mathbf{0}$ & 150 & 500 & 500 & 0.1 \\
\hline 4 & - & 500 & - & 99 & & & & & & & & \\
\hline 5 & - & 500 & - & $\mathbf{0}$ & & & & & & & & \\
\hline
\end{tabular}


Freeman J Cook and Luke M Mosley, Modelling effects of cracking on during drying on: acid generation and acid transport to the water column upon rewetting

Following the breaking of the drought in 2009/10 the rise in Lake Alexandrina was fortuitously rapid, so the rewetting process would have been a combination of scenarios 2 and 3, and may have resulted in a reduced flux of acid from sediments to the lake. Combined with the alkalinity of the lake water, this meant that Lake Alexandrina did not become acid, except in isolated areas on the lake margins (Mosley et al. 2014).

\section{CONCLUSIONS}

A simulation model has used to show that the formation of cracking in pyritic sediments during drying will result in increased formation of acidity. The amount of acidity formed increased linearly with time, with radius of the peds formed, with the depth of the cracks and with depth of the water table.

Upon rewetting of the sediments the greatest amount of acidity will be lost to the lake water if the water table is allowed to rise from the bottom of the ped, discharging the acidity through the crack and top of the ped. The least acidity is lost to the lake water if the surface and cracks of the peds can be rapidly inundated.

This suggests that management of rewetting which results in rapid inundation of acidic sediments is best to minimize acidity release to lake water.

\section{REFERENCES}

Cook, F.J. (2011). Lake Alexandrina and Lake Albert: Analysis of groundwater measurements and estimation of acid fluxes. CSIRO: Water for a Healthy Country National Research Flagship Report, 62 pp.

Cook, F.J., McLachlan, G., Leyden, E. and Mosley, L. (2011). Physical properties of soils/sediments of Lower Murray Lakes and modelling of acid fluxes. CSIRO: Water for a Healthy Country National Research Flagship Report, 60 pp.

Cook F.J. and Moseley L (2012). Modelling of acidic solute fluxes from sediments to the water column in the Lower Lakes of South Australia. Freeman Cook and Associates, Report, 66pp.

Cook FJ and Mosley L (2013). Modelling acidic solute fluxes to the water column in the lower lakes. MODSIM13 20th International Congress on Modelling and Simulation, Adelaide, Australia, 1-6 December 2013 www.mssanz.org.au/modsim2013, 1763-1769.

Earth Systems (2010). Quantification of acidity flux rates to the Lower Murray Lakes. Prepared by Earth Systems Consulting Pty. Ltd. for the SA Department of Environment and Natural Resources, Adelaide. Earth systems 2010, 171pp.

Fitzpatrick, R.W., Shand, P., Marvanek, S., Merry, R.H., Thomas, M., Raven, M.D., Simpson S.L. and McClure, S. (2008). Acid sulfate soils in subaqueous, waterlogged and drained soil environments in Lake Albert, Lake Alexandrina and River Murray below Blanchetown (Lock 1): properties, distribution, genesis, risks and management. CSIRO Land and Water Science Report 46/08, 183pp.

Hipsey, M.R., Bursch, B.D., Coletti, J. and Salmon, S.U. (2010). Lower Lakes hydro-geochemical model development and assessment of acidification risks. Prepared by University of Western Australia for SA Water, Adelaide, 79pp.

Hipsey M, Salmon U, and Mosley LM (2014). A three-dimensional hydro-geochemical model to assess lake acidification risk. Environmental Modelling and Software, http://dx.doi.org/10.1016/j.envsoft.2014.02.007.

Mosley LM, Zammit B, Jolley A, and Barnett L (2014). Acidification of lake water due to drought. Journal of Hydrology. 511: 484-493.

Rigby, P.A., Dobos, S., Cook, F.J. and Goonetilleke, A. (2006). The role of organic matter in framboidal pyrite oxidation. The Sci. Total Environ. 367:847-854. 